\title{
Basic and Combined Economic needs Monitoring in the Industry Development Support
}

\author{
Dmitry Silka ${ }^{1, *}$ \\ ${ }^{1}$ Moscow State University of Civil Engineering, 129337 Yaroslavskoe sh. 26, Moscow, Russia
}

\begin{abstract}
The evolution of economic processes and phenomena occurs cyclically with occasional deceleration or acceleration. In general, this development is accompanied by all known phases of business activity. The article reveals a new evaluation mechanism of the achieved results of the business activity growth, based on the determination of the current economic organization structure generation, the criteria for economic needs and interests. This approach allows us to critically assess the growth limits, and to form the conditions for further progressive development.
\end{abstract}

\section{Introduction}

The formation of economic intercourse both in the whole country and in the sectoral format predetermines business activity and related processes of economic cycles. On the basis of the author's research it has been stated that the existing complex of economic intercourse that determines business activity factors and business cycles is reflected in the existing economic organization structure.

\section{Basic and Combined Economic needs Monitoring}

Economic organization structure predetermines business activity cycle in the investment and construction sector depending on the existing potential of economic needs and interests. For example, at a certain stage of Russia's recent history the government came to a conclusion that the society had the need in the shared financing of the construction. Such schemes had been implemented spontaneously in the contract form of "the construction at the stage of excavation". But the society had covert needs to improve the situation with transactions security. Subsequently, due to the state involvement, these schemes were documented in the regulated shared financing schemes (Federal Law - 214). In this case the state role in supporting business activity became obvious, though it was not active enough. There is another example. If we define a modern economic organization structure, where the advanced role of science and innovations is acknowledged, it is possible to identify economic needs, the potential of which is capable of helping to solve a lot of problems. As a variant, these needs can provide housing for workers in the sphere of education and

\footnotetext{
* Corresponding author: w220@yandex.ru
} 
science. First and foremost, creating a mechanism to meet their interests will be the peculiarity of the economic organization structure. It will also be able to afford to create the conditions for business activity with the use of innovative ideas and solutions. This example expresses the potential of the economic structure needs more clearly, where the economic needs predetermine business cycle, etc. Hence, identifying of latent and explicit economic needs within the existing economic organization structure becomes absolutely necessary for business activity and business cycle control. In turn, business activity will have clear prerequisites for growth, if at the same time the existing economic structure meets the following criteria:

- latent and explicit economic needs of the state and society have been identified and are systematically identified;

- in each case, before we start the search for the ways to satisfy these needs it is admitted and taken into account that the identified needs are not finite, and in order to meet those the largest possible number of different economic needs related to each other should be identified;

- there is a clear ultimate economic need (for example, innovations in the industry), and another basic need (housing for science workers) has been identified, and taking them both into account we can generate a lot of different economic needs interconnected with each other;

- while identifying a finite need other economic requirements are being identified.

When comparing different economic structures, the structure will dominate (that is it will have the largest number of growth factors of business activity) if it has the highest level / criterion of combined economic needs included in the given basic economic need of the society (of the real sector of the economy, industry, sphere of activity, a group of entrepreneurs with consolidated interests etc.). All combined economic needs and the basic need have clear relationships and the scheme to meet the interests in sequence.

Indicator- "level /criterion of the combined economic needs included in the basic need" - appears in the form of the systematically important criterion if we do mean the concept of "the combined economic needs included in the basic need." If we consider the situation with the development of the standard technical documents regulating the development of the construction industry, where the basic need is the stimulation of innovations, the consideration of the needs will be the criterion. (The details are missed intentionally.):

1) the needs of the state and industry administrating authorities;

2) the needs of the scientists and the experts in the relevant sphere of knowledge;

3) the needs of the scientific and research organizations;

4) the needs of the enterprises of the construction sector designing and building up the completed construction products;

5) the needs of the construction products commercial users.

This example has been given for illustrative purposes only. To control business activities within the framework of the economic organization structure it is necessary to state that the criterion (C) in the development of the standard technical documents in the construction is a compulsory record keeping of the economic needs, the minimum quantity of which covers the above list of five items (taking into account decomposition $C=5 \mathrm{x}$, where $\mathrm{x}$ is a fixed number of combined needs included in the basic need). In turn, the existing economic organization structure can be diagnosed on the compliance of the combined economic needs (included in the given basic economic need) with certain criteria. Next, we can define that the given economic structure refers to the first generation of the satisfying economic needs (as an option, according to the example above, criterion $\mathrm{C}=5 \mathrm{x}$ ). When we reach a new level of criterion $(\mathrm{C}=6 \mathrm{x})$, the economic structure will refer to the second generation, etc. But in general, the proposed approach aims at achieving the system of classification of the economic organization structures in the investment and construction 
field or in any other fields of the live economy sector. Economic organization structures are classified according to generations and dominant management entities. Generations depend on the criteria of the combined economic needs. The practical examples confirm that the satisfying of the economic needs growth is really a trend which scientists and economists are interested in worldwide. So, systematic measures are being developed for that. As an option, a complex of appropriate tools is included into the "Open Data" concept.

Both economic organization structures and economic entities are not isolated from each other. It was stated that for different economic structures transfer of knowledge and competencies is peculiar. Therefore, a variety of production intercourse, which represents the specific economic organization structures, may reflect growing interconnections that will also result in business activity. The increasing relationships between the economic structures allow an increase in the level / criterion of combined economic needs included in the basic need, and they also become a prerequisite for the growth of business activity. It is a good place to start the research of the generations of the existing economic structure in the investment and construction industry with the beginning of the 1990 s period, when the economy had transformed into a market form. The study of the earlier period has a more scientific and educational purpose than a practical one.

The economic organization structure in the construction [1] has the characteristics, the content of its description both at the level of the managed systems and at the managing systems level. Managed systems characteristics of the economic organization structure are: 1) the types of the construction products which are being built, the types of works and services; 2) the types the physical resources, labour force, finances and other resources being used; 3) the construction technologies being used; 4) organizational mechanisms of construction activities; 5) the consumers of the completed construction products, works and services; 6) engineering systems and communications either centralized or local and the other. They have been reflected in the investment and construction activities projections, synthesized and shown above. We will consider and justify the methodology for determination of the managed systems characteristics in more details, giving an example of the description of the expectable economic organization structure.

So, for example, the economic organization structure has been identified, which is based on the real estate development business.

The implementation of the structure requires: 1) a complex of the capitalization of construction resources mechanisms for the complete project of the construction cycle, including the sales of the completed projects on the market; 2) the use of property, including land for the construction process; 3) the use of long-term investment resources and the relevant financial tools; 4) the use of both a wide range of physical resources and appropriate tools of inventory and logistics management; 5) a complex of certain categories of labour resources; 6) the level and the rate of the personnel employment on the site facilities; 7) the statutory regulation system of the types of works; 8) the state involvement in the strategic issues; 9) the resources taking into account the specifics of the construction process; 10) the application of innovations for enhancing the construction activity efficiency taking into account the duration of the construction process full cycle. Each of the ten points corresponds to the identified projections.

In the same way we can describe the economic organization structure, which is based on the cooperative activity, or the economic organization structure based on the share in the capital mechanisms of the households, etc. In fact, it confirms the possibility and adequacy of the description of the managed systems characteristics of the economic organization structure through the investment and construction activities consideration projections.

Due to the fact that the economic organization structure in construction is defined by the production relations, the managing systems characteristics are described right at the level of the subject relations. Describing the subjects of the economic organization structure we can 
distinguish: 1) the individual households that do not have large savings and investment resources; 2) individual households united by common interests and representing the potential in terms of possession of investment resources for regular organizing of the construction processes; 3 ) professional investment and construction institutions that do not have significant investment resources, but that are capable of attracting and developing the capital investments; 4) professional domestic investment companies, which are able to implement large-scale construction programs on the basis of the availability of their own adequate investment resources; 5) professional foreign investment companies, which are able to implement large-scale construction programs on the basis of the availability of their own adequate investment resources; 6) the state and specialized institutions implementing the investment and construction activity.

So, basing on the achieved results we will state that the category of the economic organization structure is of great interest for the research of business activity, its causes and performance. The criterion proposed above - "level /criterion of the combined economic needs included in the basic need" - belongs exactly to the economic organization structure, and as a result it specifies the business cycle parameters. Due to the dominance of the economic structure stability over the business cycle, identification of economic organization structures is the method to introduce and consider a higher level of abstraction in order to clarify the mechanism of the business cycle advent. As it is known, abstraction is a "distraction from non-essential sides, properties, connections of an object (thing or phenomenon) during the cognitive process in order to highlight their essential, inherent characteristics. The degree of abstraction of the discussed concept is called the level of abstraction. And depending on the goals and objectives we can speculate about the same object at different levels of abstraction. The need for abstraction is defined by the situation where the differences between the intellectual nature of the problem and the existence of the object in its concreteness become apparent " [2, 3].

The scope of business activity is determined by a complex of the construction types within the existing economic organization structures, which have common features. The economic interests in the framework of the economic organization structures should facilitate innovation activity in the construction sphere, where innovation activity is considered to be a combination of growth factors. Hence, business activity cycle will have positive trends, there will be prerequisites for the transition to a new phase with an efficiency increase of the investment and construction activities, the potential for investment and construction activities will be unlimited.

The manifestation of innovations is implemented improvements providing high-quality growth of efficiency of construction processes and construction products, works and services demanded by the market. A new or significantly improved product or a process of construction, a new sales method or a new organizational method in business practices, in workplace organization or in external relations all introduced in use are also innovations. Finally, not every improvement or a new development represents an innovation, but the only one that significantly (fundamentally) increases the efficiency of the current system. [4-8].

Thus, if it is obvious that business activity should be provided with innovations then the important questions arise: what should be a source of innovations, and what kind of relationships will facilitate innovation activity. Generations of the economic organization structures are of a key importance here. Some growth in the economy can occur within the economic structure of one generation without transiting to a new economic structure of a higher generation basing on activating of various potentialities, etc. We can even simulate the situation where economic growth continues while economic structure has transited to a lower generation level. We can assume that it is a transition from market instruments to a limited complex of administrative procedures. But we keep to the view that such situations 
do not occur simultaneously with the growth of innovations in economy. The transition both to the system of management and to the economic organization structure of a higher generation on the one hand and the growth of innovative economy on the other hand are compatible conditions. They also predetermine long-term growth factors at large.

The source of innovations is in the relations system of the economic organization structure. The development of innovations is a difficult process which requires both scientific research and theoretical substantiation and practical implementation. In this regard, if there are no innovations in the identified economic organization structures, in the determined content of the economic intercourse and in the achieved economic interests, it means that the business cycle is not accompanied by an innovative makeup. Thus, to facilitate a potential for growth in the business activity cycle there must be innovation processes within the economic organization structures of the investment and construction activities. Hence, identification and research of the innovative components of the economic structure are the most primary objectives during the analysis of economic organization structures. Since the development of innovations is a specific activity requiring considerable resources withdrawal from the production process we assume that primarily economic organization structures both of the state and private business without isolation from each other can generate the necessary innovations for the development of the construction industry.

It is obvious that the development of innovations plays an important part in business activity and hence the economic structure that provides the most favourable conditions for innovations and is characterized by a new generation of the economic structure is capable of becoming dominant in the economy. But in order to identify the economic structure facilitating the development of innovations we should analyse in detail the category of the economic organization structure itself. First of all, each structure requires selfidentification. To do this we will reveal insights into common attributes and properties of the economic organization structure in the construction industry.

The survey showed that economic organization structures are a structured economic relations complex of economic entities, to which the processes of satisfying economic interests are inherent in accordance with the existing competencies. The presence of business activity in the relevant cycle phase means both the development of construction products in general and the presence of the expanded reproduction process in system. And in turn, special aspects of the expanded reproduction process may be revealed within the economic organization structure. The author revealed the insights into this issue in more details in the article [3].

Since the essence of economic relations and of satisfying economic interests processes is revealed by means of economic organization systems analysis hence through the understanding of the nature and the causes of the economic relations in the economic structure it is possible to identify the causes of the business cycle. Economic organization structures have certain characteristics and attributes in connection with the objectivity of the economic structures in the investment and construction sector.

After analyzing the main basic definition of the "attribute" [2, 3], the concept of the economic organization structure attribute can be expressed as follows.

Firstly, the characteristic of the economic organization structure is such a specific feature of this category by means of which we can determine that this is the economic organization structure exactly.

Secondly, we can also note that the attribute of the economic organization structure is a distinctive feature of the economic organization structure among other categories.

Thirdly, the attribute of the economic organization structure is the feature of the structure which we can recognize, determine or describe which represents the certain property or the designation of the economic organization structure. 
According to the analysis of the established definitions properties differ from the attributes in that they are a complex of characteristics, inherences and peculiarities of an object or a phenomenon which allow us to clarify the essence of the identified object, phenomenon and other.

So firstly, the property of an economic organization structure is a characteristic or a complex of characteristics of the economic organization structure, which indicate a distinctive feature of the structure.

Secondly, the property of an economic organization structure is one of the quality aspects considering that the quality is permanent in the object (phenomenon, etc..) while properties may or may not come out.

Economic organization structures can have a great variety of properties. Generation of the economic structure is also its property which is a priori assigned and permanently inherent.

Thus, the attribute of the economic organization structure enables us to answer the question whether or not the economic organization structure is an economic structure, and thus to distinguish it from other categories. The attribute is based on the double opposite characteristics of the object, phenomenon and other. And only one characteristic can be true whereas the other one should be false.

The purpose and the final outcome of the investment and construction activity are to create the completed construction products. Therefore, during the analysis of any economic organization structure in the investment and construction industry it is necessary to make sure that, firstly, the economic structure is connected with the economic processes, in particular, with a certain type of mobilization, investment, development and capitalization of construction resources, and secondly, with the organizational processes (via the system of economic intercourse), in particular, with a certain type of building production. At the same time in favour of confirming mentioned above we will use the argument taking into consideration that the economic activity of the society expressed as a complex of relations in the system of production, distribution, exchange and consumption is the basic concept of the economy [2].

\section{Conclusions}

So, we can assume that it is feasible to define the economic organization structures attributes through a detailed analysis of the construction methods of production and the tools of mobilization, investment, development, and capitalization of resources.

Based on these statements and realizing that the growth of business activity depends on the transfer of the economic structures from one generation to a higher generation, we can note that the growing needs of the society are expressed in the automatic growth of the criteria of the combined economic needs included in the basic need. Therefore, in order to facilitate the progressive development of the society it is necessary not only to identify the spheres of economic efficiency increase of various processes and phenomena, but also to offer new needs, interests and the ways to satisfy those. The idea of the research to fix the criteria relying on the basic needs and to identify the generation of the economic structures and inherent attributes and properties gives a very objective and sustainable approach, and the system of knowledge to offer favourable conditions for economic and industry fields growth.

\section{References}

1. N.Y. Yaskova, Bulletin of Irkutsk State Technical University, 11(70), 278-280 (2012) 
2. A.N. Azriliyan, Large Economy Dictionary (Institute of New Economy, Moscow, 2002)

3. N.Y. Yaskova, D.N. Silka, Bulletin of Irkutsk State Technical University,11 (2012)

4. S.I. Agabeyov, D.I. Kokurin, K.N. Nazin, Innovations in Russia: systematic institutional analysis. 2nd ed. Corr. (TransLit, Moscow, 2011)

5. A.E. Varshavsky, Problematic innovations: the risks for mankind. Economic, social and ethical aspects (LENAND, Moscow, 2014)

6. J.V. Vertakova, E.A. Alpeeva, I.F. Ryabtsev, Progress and innovations: analysis of systemic interdependence: a monograph (INFRA-M, Moscow, 2014)

7. I. Miloslavskii, Izvestia, 99, 4 (2009)

8. R.M. Nizhegorodtsev, Information economy. Book 1. Information universe: Information bases of economic growth (ICS RAS, Kostroma, 2002) 